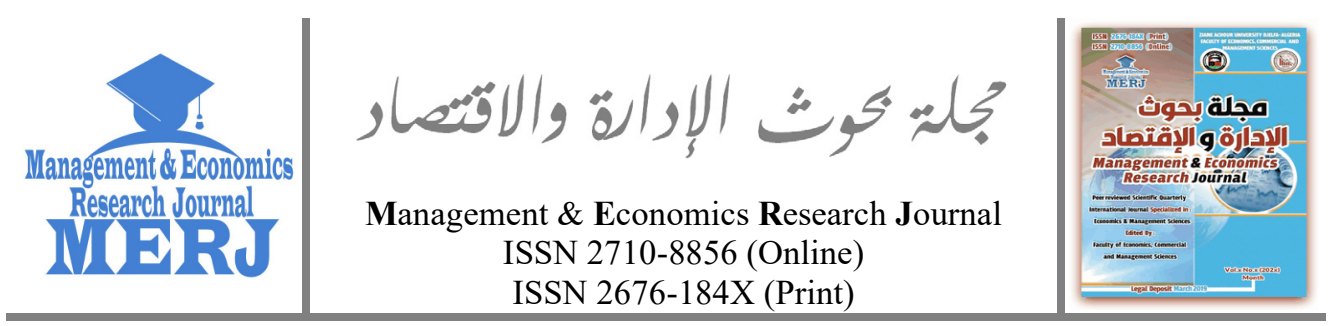

Vol. 3 No. 2 (2021), pp. 88-103

https://doi.org/10.48100/merj.2021.158

Check for updates

\title{
Healthcare Financing and Health Outcomes: Analysis of Oil-Producing Countries in Africa
}

\author{
Olaide Sekinat Opeloyeru ${ }^{\bullet}{ }^{\oplus}$, Nurudeen Abiodun Lawal ${ }^{2}{ }^{\oplus}$, \\ Kehinde Kabir Agbatogun ${ }^{3}$ (1) \\ ${ }^{1}$ lecturer II, Tai Solarin University of Education (Nigeria) \\ $\triangle$ dasola2004@gmail.com \\ ${ }^{2}$ Senior Lecturer, Tai Solarin University of Education (Nigeria) \\ \naf_lawal@yahoo.com \\ ${ }^{3}$ lecturer I, Tai Solarin University of Education (Nigeria) \\ $\bowtie$ agbatogunkk@tasued.edu.ng
}

Received: 17-02-2021

Accepted: 11-04-2021

Published online: 13-04-2021

How to Cite:

Opeloyeru, O. S., Nurudeen Abiodun, L., \& Kehinde, K. A. (2021). Healthcare Financing and Health Outcomes: Analysis of Oil-Producing Countries in Africa. Management \& Economics Research Journal, 3(2), 88-103. https://doi.org/10.48100/merj.2021.158

\begin{abstract}
:
The study's primary concern is healthcare financing and health outcomes in the major oil-producing countries in Africa. We used the data sorted from World Development Indicators (WDI) to identify the effect of four different health expenditures on the rate of mortalities on maternal, under-five, infant, neonatal, and life expectancy at birth through random and fixed-effect models. This paper also takes cognizance of the environmental variable (pollution) common to the top 10 oil-producing countries in Africa. Our findings showed that high health expenditure from government, private and external sources improved health outcomes, while health expenditure
\end{abstract}

- Corresponding author: Tai Solarin University of Education (Nigeria).

[ $₫$ dasola2004@gmail.com]

(C2021 the Author(s). This is an open-access article distributed under the terms of (CC BY-NC 4.0) which permits use, distribution and reproduction in any medium, provided the original work is properly cited and is not used for commercial purposes. 
Opeloyeru, O. S.,

Lawal, N. A., \&

Agbatogun, K. K.

Healthcare Financing and Health Outcomes: Analysis of

Oil-Producing Countries in Africa

from out of pocket is detrimental to health outcomes. Also, the environmental variable has a negative impact on life expectancy. The paper's outcome indicated a need to reduce environmental pollution, increase health expenditure from government, private, and external sources and reduce out-of-pocket payments in the selected areas.

Keywords: Health Outcome, Pollution, Life Expectancy and Government.

JEL Codes: C1, H51, I12, Q5.

\section{Introduction}

Healthcare financing is one of the most crucial components of the health system because, without expenditure, staff emolument, medical equipment, and many health facilities will not be in place. It yields the inputs and economic algorithm for the functioning of the health system. It serves as a causal element of health system performance in terms of outcomes on health, equity, and efficiency. In most countries, health outcomes are usually used to evaluate a country's health status, ranging from the mortality rate in maternal, infant, neonatal, adult, and under-five to life expectancy. Globally, the African continent shoulders the bulk of morbidity and mortality, which reflects the level and style of spending on health. Although, the continent is beginning to have changes in healthcare financing mechanisms to catch up with sustainable development goals (SDGs) and global expectations.

In the last decade, economic growth in Africa, especially among non-resource-intensive economies, has been noted to be faster than expected. For instance, the continent's real production growth recovered from global and domestic shocks in 2016, with progressive growth rates, from 2.2 per cent in 2016 to 3.6, and 4.1 per cent in 2017 and 2018, respectively. Despite growth rate increases, health outcomes in this country continue to show disparities relative to developed countries in other areas. Although, there has been improvement in health outcomes in a bid to meet up with health-related SDG goals. The healthy life expectancy in the region moved from approximately 61 years to 54 years between 2012 and 2015, with a reduction in the gap in healthy life expectancy from 27.5 to 22 years between the top and lowest performing countries (WHO, 2018). Between 2000 and 2015, the level of morbidity and mortality had significantly reduced as disability-adjusted life years (DALYs) as a response from the common ten causes of illness reduced to more than half, which is pushed by a decrease in malaria, HIV/AIDS, and diarrheal diseases (WHO, 2018). As a result, the death rate from the common ten causes of illness also reduced from 87.7 to 51.3 per 100,000 populations in the same period. Despite 
\begin{tabular}{l|l|l} 
Management \& Economics Research Journal & Vol. 3 No. 2 (2021) & pp. 88-103 \\
\hline
\end{tabular}

improvements in some of the noted crude health outcomes, the region is still at the lower pyramid in terms of health outcomes compared to the rest of the world due to the high burden of diseases from infectious diseases, violence/injuries and non-communicable diseases. For instance, in 2016, African countries accounted for eighty per cent of the burden universe of HIV among adolescents between ages 10 and 19 years, and more than 70 per cent of new HIV infections are among adolescent girls. Out of the 57 per cent of maternal deaths in the world resulting from pregnancy-related complications, Africa accounts for 33 per cent, giving the region the highest maternal mortality ratio in the world. Of about 6 million children dying before their fifth birthday from pneumonia, diarrhoea, measles, HIV, tuberculosis and malaria, the region also accounts for 50 per cent of underfive deaths.

- Paramount among factors hindering access to healthcare quality in Africa, as identified by the World Health Organization (WHO), are:

- Lack of healthcare funding.

- Shortage of services.

- Costly medicines due to imported pharmaceutical products (approximately 70\% imported).

- Lack of qualified staff.

Funding healthcare is the bedrock of the identified problems. One of the major constraints from the shortage of funds in the health sector of most African countries is that the policies and techniques that promote the healthcare financing systems constitute problems. WHO (2013) ascertains that out-of-pocket payments constitute at least forty per cent of the aggregate health expenditure in about half of the African countries, which has a potential tendency to lead to catastrophic health expenditure and impoverishment for some households in the course of accessing quality healthcare. Limited access to quality healthcare has contributed to the health status of many African countries, which has a major impact on many macro and microeconomic variables.

With a central focus on reduction in reliance on) out of pocket payment) and consequently increased access to healthcare and increment of financial risk protections as part of objectives of Universal Health Coverage (UHC), the African leaders agreed to allocate 15 per cent of the total budget to health at Abuja Declaration in 2001. Many African countries are still struggling to achieve this target recently, but the average per capita health spending rose from $\$ 70$ in 2000 to $\$ 160$ in 2014. The difficulty in achieving this target may arise due to difficulties in raising public funds from many African countries due to the informal sector of their economies, but what about some oil-dependent countries where revenue is easily generated 
Opeloyeru, O. S.,

Lawal, N. A., \&

Agbatogun, K. K.

Healthcare Financing and Health Outcomes: Analysis of

Oil-Producing Countries in Africa

through offshore and onshore taxes? Calain (2008) averred that less growth is achieved by countries with endowed natural resources compared to no endowed countries and usually has adverse health outcomes due to the destruction of public health stemming from the exploration of natural resources.

Handful studies on health outcomes and healthcare financing in Africa have demonstrated that the size of government spending, private spending, and donor's fund on healthcare has a significant positive/negative impact on health outcomes, which invariably has a recursive effect on individuals' labour and non-labour activities (Calain, 2008; Anyanwu \& Erhijakpor, 2009; Nwakanma, 2013; Akinci et al.,2014; Asbu et al.,2017; Bein et al.,2017; Nikoloski \& Amendah, 2017). However, many of these studies ignored the environmental variable resulting from exploration that causes damage to general health and affects outcomes on health in resourceendowed countries in Africa. Thus, this study focuses on the effect of healthcare financing on health outcomes in selected oil-producing countries in Africa, taking cognizance of the mediating role of environmental pollution in the selected areas.

\section{Stylized facts}

This sub-section discusses stylized facts about average gross domestic product (GDP), total health expenditure (THE), health expenditures from out of pocket, from government, from private, from external, life expectancy, maternal mortality rate, under-five mortality rate, infant mortality rate, neonatal mortality rate, and $\mathrm{CO}_{2}$ emissions in 10 selected oil-producing African countries ${ }^{1}$ between the periods of 2000 and $2017^{2}$ (see Table 1). Equatorial Guinea is ranked least, with a GDP of $\$ 12,100$ million. In comparison, South Africa has the highest GDP of $\$ 356,981$ million, followed by Nigeria, Egypt, Algeria, Gabon, Libya, the Republic of Congo, Sudan, and Angola, respectively. Among these ten countries, the share of health expenditure from the government as a share of GDP ranges between 3.49 per cent and 0.34 per cent, with South Africa having the highest share of health expenditure from GDP. As shown in Table 1, health expenditure from the government as a percentage of THE shows that Algeria has the highest percentage of 71.46 per cent and the least of 8.86 per cent in the Congo. Even though Nigeria is ranked second with an

\footnotetext{
${ }^{1}$ South Africa, Algeria, Libya, Egypt, Sudan, Nigeria, Angola, Equatorial Guinea, The Republic of Congo and Gabon (these countries are the top 10 oil producers in Africa).

2 The selected periods are based on availability of data.
} 
\begin{tabular}{l|l|l} 
Management \& Economics Research Journal & Vol. 3 No. 2 (2021) & pp. 88-103 \\
\hline
\end{tabular}

average GDP of $\$ 299,358$ million, Nigeria accounts for the highest private health expenditure as a percentage of THE and highest health out-of-pocket payments of 76.93 per cent and 75 per cent, respectively, among the selected ten African countries. While Congo has received more external health funding on average, Algeria and Libya received the least among these countries.

Table 1. GDP and health funding sources between 2000 and 2017

\begin{tabular}{|c|c|c|c|c|c|c|c|c|c|c|}
\hline & Nigeria & Algeria & Angola & Libya & Egypt & Sudan & $\begin{array}{l}\text { Equatorial } \\
\text { Guinea }\end{array}$ & $\begin{array}{l}\text { Congo, } \\
\text { Rep. }\end{array}$ & $\begin{array}{l}\text { South } \\
\text { Africa }\end{array}$ & Gabon \\
\hline $\begin{array}{l}\text { GDP (current } \$ \\
\text { million US) }\end{array}$ & 299,36 & 137,25 & 74,09 & 47,91 & 186,44 & 53,38 & 12,10 & 21,89 & 356,98 & 12,14 \\
\hline $\begin{array}{l}\text { Government } \\
\text { health } \\
\text { exp. (\% of GDP) }\end{array}$ & 0.58 & 3.46 & 1.78 & 2.34 & 1.57 & 1.54 & 0.43 & 0.34 & 3.49 & 1.43 \\
\hline $\begin{array}{l}\text { Government } \\
\text { health } \\
\text { exp. (\% of } \\
\left.\text { THE }^{3}\right)\end{array}$ & 16.96 & 71.46 & 53.55 & 64.88 & 33.18 & 30.92 & 23.10 & 8.86 & 47.43 & 43.97 \\
\hline $\begin{array}{l}\text { Private health } \\
\text { exp. (\% of THE) }\end{array}$ & 76.93 & 28.50 & 43.81 & 35.08 & 63.67 & 66.31 & 72.60 & 59.41 & 50.56 & 49.49 \\
\hline $\begin{array}{l}\text { Out of pocket } \\
\text { (\% of THE) }\end{array}$ & 75.00 & 26.70 & 31.1 & 35.10 & 62.2 & 62.80 & 67.90 & 51.40 & 10.10 & 40.30 \\
\hline $\begin{array}{l}\text { External exp. } \\
(\% \text { of THE) }\end{array}$ & 6.08 & 0.04 & 2.64 & 0.04 & 0.85 & 2.77 & 4.30 & 31.74 & 2.00 & 1.53 \\
\hline
\end{tabular}

Source: World development indicators (WDI, 2020)

Among the ten selected oil-producing countries, closer scrutiny of Table 2 shows that Nigeria performs worst in all the identified health indicators, with the highest $\mathrm{CO}_{2}$ emissions of 28,193 (1000 metric tons). On average, life expectancy for Algeria recorded the highest value of approximately 73.81 years, which is very close to that of the United States in 2017 of about 78.54 years. Libya and Egypt are ranked second and third in life expectancy of approximately 71.42 and 70.15, respectively, while Nigeria recorded an average life expectancy of about 50 years. The country with the lowest rate of mortalities in maternal, infant, under-five and neonatal among these countries is Libya, but it was ranked sixth per $\mathrm{CO}_{2}$ emissions. As shown below, not all countries under consideration with high $\mathrm{CO}_{2}$ emissions perform poorly with regard to their health indicators. While some countries recorded high $\mathrm{CO}_{2}$ emissions with poor health indicators, others have relatively high $\mathrm{CO}_{2}$ emissions with average or good health indicators, which could result from their health funding patterns discussed in

${ }^{3}$ Total health expenditure (THE) 
Opeloyeru, O. S., Lawal, N. A., \& Agbatogun, K. K.

Healthcare Financing and Health Outcomes: Analysis of Oil-Producing Countries in Africa

Table 1.

Table 2. Health indicators and $\mathrm{CO}_{2}$ emissions between 2000 and 2017

\begin{tabular}{|c|c|c|c|c|c|c|c|c|c|c|}
\hline & Nigeria & Algeria & Angola & Libya & Egypt & Sudan & $\begin{array}{l}\text { Equatorial } \\
\text { Guinea }\end{array}$ & $\begin{array}{l}\text { Congo, } \\
\text { Rep. }\end{array}$ & $\begin{array}{l}\text { South } \\
\text { Africa }\end{array}$ & Gabon \\
\hline $\begin{array}{l}\text { Life } \\
\text { expectancy } \\
\text { at birth }\end{array}$ & 50.00 & 73.81 & 55.84 & 71.42 & 70.15 & 61.81 & 55.49 & 55.60 & 56.63 & 62.23 \\
\hline $\begin{array}{l}\text { Maternal } \\
\text { mortality rate } \\
\text { (per } 100,000 \\
\text { live births) }\end{array}$ & 894.35 & 145.52 & 625.13 & 10.45 & 44.46 & 387.70 & 439.74 & 763.33 & 123.53 & 334.83 \\
\hline $\begin{array}{l}\text { Infant } \\
\text { mortality rate } \\
\text { (per } 1,000 \\
\text { live births) }\end{array}$ & 86.53 & 26.14 & 85.76 & 16.61 & 26.55 & 54.19 & 85.34 & 88.42 & 42.73 & 44.84 \\
\hline $\begin{array}{l}\text { Under-five } \\
\text { mortality rate } \\
\text { (per } 1,000 \\
\text { live births) }\end{array}$ & 139.8 & 30.44 & 138.62 & 19.46 & 32.12 & 81.68 & 121.16 & 124.04 & 63.54 & 66.57 \\
\hline $\begin{array}{l}\text { Neonatal } \\
\text { mortality rate } \\
\text { (per } 1,000 \\
\text { live births) }\end{array}$ & 39.73 & 18.12 & 39.24 & 10.23 & 16.73 & 33.28 & 37.36 & 34.06 & 14.04 & 25.52 \\
\hline $\begin{array}{l}\mathrm{CO}_{2} \\
\text { Emissions } \\
\text { (1000 metric } \\
\text { tons) }\end{array}$ & 28,19 & 24,41 & 6,90 & 9,22 & 15,48 & 4,45 & 15,48 & 3,95 & 19,92 & 2,17 \\
\hline
\end{tabular}

Source: World development indicators (WDI, 2020)

\section{Literature review}

Literature abounds with the connection between health outcomes and healthcare financing relies on two schools of thought. The first one focuses on the Grossman theory of 1972, which emphasizes that spending on medical care affects health outcomes through a household's healthcare production function. Grossman argued that health is durable equity that produces an output of physical, mental, and emotional strength with the assumption that people inherit an embryonic bundle of health that reduces little by little, with the occurrence of death when the level of health drops below a particular level. Household productions produce gross investment in health capital, which depends on direct inputs (personal time of consumer), market goods (housing, diet, recreation, exercise, and medical care) and environmental variables (education of the producer). The novelty of his argument is that people demand (health) for two primary reasons: (1) consumption commodity and (2) investment commodity, in order to remove disutility from sick days and to improve the entirety of available time for market and non-market activities. However, in demand for health, demand 
\begin{tabular}{l|l|l} 
Management \& Economics Research Journal & Vol. 3 No. 2 (2021) & pp. 88-103 \\
\hline
\end{tabular}

for health may reduce with an increase in shadow price, while the quantity of medical care demanded may increase subsequently. Based on his idea, Riman and Akpan (2012), Kulkarni (2016), and Rana et al. (2018) have adopted socioeconomic and environmental factors as inputs in the production of health goods to explain the link between health outcomes and healthcare financing with different crude health outcomes such as rate of mortalities on maternal, under-five, infant, adult, neonatal, quality-adjusted life years (QALY) and life expectancy. The second school of thought was from Martin et al. (2008) that the health policymakers decide on how to allocate the health budget with each health production function associated with every health programme of care, suggesting the connection between health outcomes and health spending. They assumed that a health policymaker should maximize the total social welfare function that subsumes health outcomes subject to health spending budget constraints and health production function. The outcome of the optimization should be that an increase in expenditure should yield improvement in health outcomes. A variant of this idea also sprouted from Calain's (2008) analytical framework through corporate social responsibilities in a resource-curse environment. He claimed that in a resource-curse environment, policymakers should maximize total social welfare (healthcare financing and healthcare projects), As their activities in that environment /country have some damaging effects on public health. This mandates corporate sectors to engage in healthcare financing through corporate social responsibility. Given this claim, this paper includes an environmental variable to ascertain its role in health outcomes.

Different results have emerged from various methodologies applied by different researchers on the variant of this study. Only some studies have used comprehensive descriptive analysis for cross-country data to compare the level of healthcare financing across the countries in the same region (Nwakanma, 2013; Asbu et al., 2017; Nikoloski \& Amendah, 2017). While panel pooled or fixed Ordinary Least Squares (OLS) to account for endogeneity was adopted by Gani (2008), Farag et al. (2013), Akinci et al. (2014), Kulkarni (2016) and Bein et al. (2017). However, some studies claimed that it is good to account for cross-section dependence and heterogeneity by including cointegration relationships among variables, which called for the application of two-stage least squares (2SLS), Error Correction Model (ECM), Linear Mixed Model, Panel Autoregressive distributed lag, fully modified ordinary least squares (FMOLS) and panel cointegration test (Martin et al.,2009; Anyanwu \& Erhijakpor,2009; Kim \& Lane, 2013; Fazaeli et al., 2016; Rana et al., 2018). Other methods applied are logistic regression for state analysis and OLS for single-country analysis 
Opeloyeru, O. S.,

Lawal, N. A., \&

Agbatogun, K. K.

Healthcare Financing and Health Outcomes: Analysis of

Oil-Producing Countries in Africa

(Riman \& Akpan, 2012; Edeme et al., 2017). Based on the methodological review, most studies used up to three variables as crude health outcomes with a fixed or random-effect model. However, this study uses up to five crude health outcomes combined with fixed and random models to predict empirical outcomes.

Empirically, different estimation methods have generated mixed findings due to different proxies used to capture healthcare financing and health outcomes. Healthcare financing proxies range from health expenditure from government, private, military, and out-of-pocket spending to external sources. In contrast, health outcomes proxies range from life expectancy, maternal mortality, under-five mortality, infant mortality, adult mortality, neonatal mortality, and reproductive health to quality-adjusted life years (QALY). For instance, Nwakanma (2013) used adult mortality rate, infant mortality rate, and life expectancy to proxy health outcomes and found that underinvestment in public health reflects the low health profile in West African countries. Studies by Martin et al. (2009), Anyanwu and Erhijakpor (2009), Kim and Lane (2013), Akinci et al. (2014), Kulkarni (2016), and Edeme et al. (2017) averred that high government spending as well as health spending from private and out of pocket, improve life expectancy and reduces infant and maternal mortalities. While Bein et al. (2017) affirmed a similar positive impact between healthcare expenditure and health outcomes, they also established that healthcare expenditure had a more powerful effect on female life expectancy than male life expectancy in Uganda, Burundi, Sudan, Eritrea, Kenya, Rwanda, Ethiopia, and Tanzania.

On the contrary, Riman and Akpan (2012) found that a rise in the incidence of out-of-pocket results in a rise in the level of infant mortality, including wide disparity and inequality in income, while Rana et al. (2018) found that maternal mortality across 161 countries investigated is significantly affected by expenditure on health. Nikoloski and Amendah (2017) empirically affirmed that private health spending does not significantly affect neonate and neonatal mortalities across 14 African countries. Other notable empirical results related to this study affirmed that expenditure on health from the public to the health sector from oil export earnings in oil countries is frequently more than private health expenditure in identical developed countries and that environmental pollution and female participation in the labour force had a negative impact on health outcomes (Fazaeli et al.,2016 \& Kulkarni, 2016).

\section{Methodology}

This study relies on Grossman's (1972) theory that spending on 
\begin{tabular}{l|l|l} 
Management \& Economics Research Journal & Vol. 3 No. 2 (2021) & pp. 88-103 \\
\hline
\end{tabular}

medical care affects health outcomes through a household's healthcare production function with an adaptation of modification from Rana et al.'s (2018) research. A variant of the health production function of the Grossman model is of the form:

$H=f(M, Z)$

Where $\mathrm{H}$ is assumed to represent the outcome of health like life expectancy at birth, rate of mortalities on an under-five, maternal, infant, and neonatal, $\mathrm{M}$ is the medical care received, and $\mathrm{Z}$ represents socioeconomic (income) and environmental factors (education and environmental pollution). In line with the Grossman model, medical care stands as one of the most important market goods of the health production function. Therefore, Rana et al. (2018) corroborate this model by suggesting that medical care has its associated prices and costs. Hence, holding all other factors constant, higher utilization of medical services is related to financing healthcare through medical care and vice versa. Therefore, the quantity and quality of medical care used that will yield health outcomes in equation (1) is a function of the sources of healthcare financing/ health expenditure (HE):

$M=f(H E)$

Health expenditure (HE) from the above function includes government expenditure on health, out-of-pocket payments, and private and external healthcare expenditures. Equation (3) is formed from equations (1) and (2):

$H=f(H E, Z)$

The main estimation model for this study is stated in functional form as equation (4):

$\mathrm{H}=\mathrm{f}$ (PGDP, PGHE, PPHE, POOPHE, PEHE, ENV)

The left-hand side variable is the dependent variable, as stated in equation 4, while the right-hand side variables are the independent variables. Where PGDP is gross domestic product per capita, PGHE represents per capita expenditure from the government on health, PPHE is per capita expenditure from private on health, POOPHE is the per capita expenditure from out of pocket on health, PEHE is the external expenditure 
Opeloyeru, O. S., Lawal, N. A., \& Agbatogun, K. K.
Healthcare Financing and Health Outcomes: Analysis of

Oil-Producing Countries in Africa

per capita, and ENV is the environmental variable representing $\mathrm{CO}_{2}$ emissions.

The data for the study were spooled from Indicators available on the World Bank data archive site. Data for health outcomes include the rate of mortalities on maternal (per 100,000 live births), under-five, infant, and neonatal measured in 1,000 live births, and life expectancy. The exogenous variables are gross domestic product per capita, government expenditure on health per capita, private expenditure on health per capita, out-of-pocket expenditure on health per capita, external expenditure per capita, and the environmental variable representing $\mathrm{CO}_{2}$ emissions is the emissions from the combustion, transmission, handling and production of biofuels and fossil fuels. The study uses fixed and random models because of the panel nature of the data and the Hausman test to determine the best model for each of the five models estimated. Based on the functional form model in equation 4, the underline econometric model for this study is specified as follows:

$\mathrm{H}_{\mathrm{it}}=\mathrm{a}_{0}+\mathrm{b}_{1} \mathrm{PGDP}_{\mathrm{it}}+\mathrm{b}_{2} \mathrm{PGHE}_{\mathrm{it}}+\mathrm{b}_{3} \mathrm{PPHE}_{\mathrm{it}}+\mathrm{b}_{4} \mathrm{POOPHE}_{\mathrm{it}}+\mathrm{b}_{5} \mathrm{PEHE}_{\mathrm{it}}+\mathrm{b}_{6} \mathrm{ENV}_{\mathrm{it}}+\varepsilon_{\mathrm{it}}(5)$

Variable names are the same as stated in functional form. Constant is denoted by $\mathrm{a}_{0}$, bs are the parameters for each independent variable used, and $\varepsilon$ is the error time. The time is represented with $t$ and $i$ denoting countries involved.

Extracted data for this paper's analysis were obtained from the indicators made available by the World Bank (WDI), which span from 2000 to 2017. The selected periods are subject to the availability of data. The crude health outcomes used in this paper are the rate of mortalities on maternal, neonatal, infant, under-five, and life expectancy. Other useful data are gross domestic product per capita, government expenditure on health per capita, private expenditure on health per capita, out-of-pocket expenditure on health per capita, external expenditure per capita and the environmental variable representing $\mathrm{CO}_{2}$ emissions. The gross domestic product per capita included here is the real GDP to capture the effect of income on health outcomes, as suggested in the literature by Farag et al. (2013).

\section{Presentation and discussion of empirical results}

This section presents empirical outcomes from the models estimated. The results are the descriptive and the fixed/ random-effects regressions adjudged from the Hausman test for each model. All data used are transformed to their natural $\log$ form before estimation. The minimum value, standard deviation, maximum value, and mean for the data used are 
\begin{tabular}{l|l|l} 
Management \& Economics Research Journal & Vol. 3 No. 2 (2021) & pp. 88-103 \\
\hline
\end{tabular}

presented in Table 3. below. The total observation among the ten countries chosen is 180 . On average, life expectancy among these countries is a unit above 60 , with a minimum of 46.27 and a maximum of 76.29. A mean value of 376.88 is recorded for maternal mortality, and minimum and maximum value ranges between 6 and 1170. It is evident that among the crude health outcomes selected, maternal mortality recorded the highest mean, followed by neonatal, while under-five mortality recorded the lowest mean among the selected countries. It is also the case that the average health expenditure from private is more than government health expenditure, which indicates that health spending from the private pocket is higher than government health spending. Additional information from this Table is that external health expenditure, on average, is deficient compared to out-of-pocket expenditure from households.

Table 3. Descriptive statistics

\begin{tabular}{llllll}
\hline Variables & Obs. & Mean & Standard deviation & Minimum & Maximum \\
\hline Life expectancy at birth & 180 & 61.29 & 8.11 & 46.27 & 76.29 \\
Maternal mortality & 180 & 376.88 & 305.35 & 6.00 & 1170.00 \\
Infant mortality & 180 & 55.66 & 29.44 & 10.6 & 122.60 \\
Under five Mortality & 180 & 26.78 & 11.36 & 6.50 & 50.70 \\
Neonatal mortality & 180 & 81.70 & 48.66 & 12.4 & 206.30 \\
Real GDP (per capita) & 180 & 5382.48 & 4546.28 & 276.25 & 20333.94 \\
Per-capita government HE & 180 & 75.57 & 77.14 & 0.18 & 325.17 \\
Per-capita private HE & 180 & 83.36 & 63.71 & 3.75 & 257.47 \\
Per-capita out-of-pocket HE & 180 & 62.48 & 48.72 & 3.21 & 240.00 \\
Per-capita external HE & 180 & 3.52 & 3.91 & 0 & 18.09 \\
C02 emissions & 180 & 11618.30 & 14107.92 & 0 & 45868.56 \\
\hline
\end{tabular}

HE represents health expenditure.

Source: Computed by the authors.

A synopsis of results generated from regression analyses is presented in Table 4. The independent variables behave differently with respect to each dependent variable under each model. Closer scrutiny of Table 4 shows that three independent variables are statistically significant for life expectancy as a dependent variable. Per capita expenditure from the government on health responds positively to life expectancy. This suggests that an increase in life expectancy is possible if government health expenditure rises. Contrarily, out-of-pocket expenditure and $\mathrm{CO}_{2}$ emissions have negative effects on life expectancy. The implication is that out-ofpocket health payments create a burden on households. A clear understanding of $\mathrm{C} 02$ emissions having a negative effect on life expectancy 
Opeloyeru, O. S., Lawal, N. A., \& Agbatogun, K. K.
Healthcare Financing and Health Outcomes: Analysis of

Oil-Producing Countries in Africa

is possible since emissions could degenerate into different life-threatening diseases. The result of the $\mathrm{C} 02$ and health outcome under life expectancy could be affirmative, as Fazaeli et al. (2016) and Kulkarni (2016) also confirm similar outcomes. A further examination of this Table shows that for maternal mortality, only per capita income is statistically significant. This indicates that mothers' mortality rate reduces by 0.22 per cent as income increases. This is a likely result as Grossman's (1972) theory suggests that spending on medical care affects health outcomes through a household's healthcare production function, as spending also depends on income.

Furthermore, all forms of health expenditure used for this analysis are found to be statistically insignificant. This suggests that health expenditure has no significant relationship with maternal mortality across the ten counties involved. This is plausible, as it was found in the study of Rana et al. (2018) across 161 countries investigated.

It is obvious from the Table that only $\mathrm{C} 02$ emissions show no statistically significant relationship with infant mortality. Also, out of the four forms of expenditure that interacted with infant mortality, only out-ofpocket health expenditure shows a significant positive relationship with infant mortality, and the other three forms of health expenditure show significant negative impacts. A percentage increase in expenditure from the government on health and expenditure from private on health and external sources will significantly reduce infant mortality by 0.99 per cent, 0.39 per cent and 0.02 per cent, respectively. The impact of income is reversed under infant mortality compared to maternal mortality, suggesting that an increase in income will statistically increase infant mortality. A plausible reason for the reversed sign may be that parents working to generate income to cater for an infant may have their own cost on the infant's health through neglect due to time constraints. All independent variables are statistically significant for the neonatal mortality rate as a dependent variable. A significant positive relationship between infant mortality and income also exists with neonatal mortality. Expenditure from the government on health, expenditure from private on health, expenditure from external sources on health and the pollution variable have a significant negative relationship with neonatal mortality.

On the contrary, out-of-pocket health expenditure positively correlates with neonatal mortality. This suggests that a percentage increase in out of pocket will increase neonatal mortality. The burden of expenditure on health from out of pocket on households may cause an increase in neonatal mortality among the ten countries investigated. The impact of environmental variables here could be negative since most under-aged are 
\begin{tabular}{l|l|l} 
Management \& Economics Research Journal & Vol. 3 No. 2 (2021) & pp. 88-103 \\
\hline
\end{tabular}

not too exposed to pollution or the exploration environment may be far from residential areas.

The under-five mortality rate as a dependent variable shows that health expenditure from out-of-pocket, external sources, government and private is statistically significant. A percentage increase in either expenditure from the government on health, expenditure from private on health or external sources on health will reduce the incidence of under-five mortality. On the contrary, for expenditure on health from out-of-pocket, an increase in out-of-pocket leads to a 0.3 per cent increase in under-five mortality. This implies that higher out-of-pocket health expenditure could be one of the major causes of an increase in under-five mortality in the selected area. Overall, the effect of health expenditure from out-of-pocket payments, private sources, external, and the government is similar for crude health outcomes based on mortalities. At the same time, the reverse is the case for life expectancy. It is also the case for $\mathrm{C} 02$ emissions that infant mortality, neonatal, life expectancy, and under-five mortalities demonstrate a similar effect on it, but with different meanings. This is because an increase in life expectancy is interpreted as a positive health outcome, while an increase in crude mortality rates is interpreted as a negative health outcome. For income, only maternal mortality shows a negative outcome, which means that an increase in income will result in a reduction in maternal mortality with a magnitude of 0.22 per cent.

Table 4. Regression results on health outcomes and healthcare financing

\begin{tabular}{llllll}
\hline $\begin{array}{l}\text { Dependent variables } \\
\text { Independent variables }\end{array}$ & $\begin{array}{l}\text { Life exp. } \\
\text { (FE) }\end{array}$ & $\begin{array}{l}\text { Maternalmrt } \\
(\mathrm{RE})\end{array}$ & $\begin{array}{l}\text { Infant mort. } \\
(\mathrm{FE})\end{array}$ & $\begin{array}{l}\text { Neonatalmrt. } \\
(\mathrm{FE})\end{array}$ & $\begin{array}{l}\text { Under5mrt. } \\
\text { (FE) }\end{array}$ \\
\hline Real GDP (per capita) & 0.0166 & $-0.2236^{* *}$ & $0.1103^{* *}$ & $0.1350^{* *}$ & 0.0584 \\
& $(0.1857)$ & $(0.0907)$ & $(0.0486)$ & $(0.0382)$ & $(0.0572)$ \\
Per capita govt. HE & $0.0330^{* *}$ & -0.0185 & $-0.9968^{* *}$ & $-0.0809^{* *}$ & $-0.1239^{* *}$ \\
& $(0.0086)$ & $(0.0433)$ & $(0.0226)$ & $(0.1776)$ & $(0.0266)$ \\
Per capita private HE & 0.0507 & -0.2138 & $-0.3914^{* *}$ & $-0.2851^{* *}$ & $-0.3550^{* *}$ \\
& $(0.0419)$ & $(0.2080)$ & $(0.1098)$ & $(0.0862)$ & $(0.1293)$ \\
Per capita OOP HE & $-0.0611^{*}$ & 0.0873 & $0.3294^{* *}$ & $0.2375^{* *}$ & $0.3216^{* *}$ \\
& $(0.0369)$ & $(0.1832)$ & $(0.0967)$ & $(0.0760)$ & $(0.1139)$ \\
Per-capita external HE & $0.0153^{* *}$ & 0.0222 & $-0.0290^{* *}$ & $-0.0205^{* *}$ & $-0.0367^{* *}$ \\
& $(0.0046)$ & $(0.0231)$ & $(0.0120)$ & $(0.0095)$ & $(0.0142)$ \\
C02 emissions & $-0.0626^{* *}$ & 0.0775 & -0.0871 & $-0.1952^{* *}$ & -0.0341 \\
& $(0.0286)$ & $(0.1354)$ & $(0.0749)$ & $(0.0588)$ & $(0.0881)$ \\
\hline
\end{tabular}

Note that $*$ and $* *$ denote variables that are statistically significant at less than $10 \%$ and $5 \%$ respectively. Mrt. Implies mortality. Values in parentheses are the standard errors, FE means fixed effects and RE means random effects.

Source: Computed by the authors 
Opeloyeru, O. S., Lawal, N. A., \& Agbatogun, K. K.
Healthcare Financing and Health Outcomes: Analysis of

Oil-Producing Countries in Africa

\section{Conclusion and recommendation}

One fundamental way of enhancing a country's health outcomes is to provide a strategic healthcare funding system to achieve equity and efficiency. Out-of-pocket healthcare expenses in Africa account for more than forty per cent of overall health spending. The undoubted outcome of having out-of-pocket payments as the primary means of channelling funds to healthcare providers in any country is an irresistible burden on the household. Outpatient-pocket healthcare payments among the ten selected oil-producing countries still form a larger part of the total health expenditure, as shown in the second section of this study. In this paper, about four primary outcomes are discernible. One of the significant results is that income plays an imperative role (negative/positive) in health outcomes, which is why most health or health-related models have an income budget constraint attached to them to form a final decision. Secondly, high out-of-pocket payments shorten the expected life expectancy at birth, which could mean that the high out-of-pocket health expenditure may affect other livelihood consumption and may be detrimental to human life. Another obvious result is that private and government health expenditures from external sources have a positive effect on health outcomes. This is obvious from the result and should be increased to reduce the negative effect of out-of-pocket on the household. In addition, the role of the environment should be taken as important to health as a result of life expectancy at birth, which indicates that a rise in $\mathrm{C} 02$ emissions lowers life expectancy. Conclusively, it should be noted that each crude health outcome behaves differently under the estimated outcomes; each health outcome should be treated with different favourable policies. It is recommended that out-of-pocket healthcare payments be reduced, and other healthcare payments should be improved to reduce the household burden. It is also advisable to control emissions in the selected areas to ameliorate life expectancy at birth through government policies.

\section{Declaration of conflicting interests}

The author(s) declared no potential conflicts of interest with respect to the research, authorship, and/or publication of this article.

\section{References}

Akinci, F., Hamidi, S., Suvankulov, F., \& Akhmedjonov, A. (2014). Examining the impact of health care expenditures on health outcomes in the Middle East and North Africa (MENA) Region. Journal of Health Finance. 41(1), 1-23. 
\begin{tabular}{l|l|l} 
Management \& Economics Research Journal & Vol. 3 No. 2 (2021) & pp. 88-103 \\
\hline
\end{tabular}

Anyanwu, J.C \& Erhijakpor, A. E. (2009). Health expenditures and health outcomes in Africa. African Development Review. 21(2), 400-433. https://doi.org/10.1111/j.1467-8268.2009.00215.x

Asbu, E. Z., Masri, M.D. \& Kaissi, A. (2017). Health status and health systems financing in the MENA region: a roadmap to universal health coverage. Global Health Research and Policy, 2(25). https://doi.org/10.1186/s41256-017-0044-9

Bein, M. A., Dogan, U., Gbolahan, O., \& Wagdi, K. (2017). Healthcare spending and health outcomes: evidence from selected East African countries. African Health Sciences, 17(1), 247-254. https://doi.org/10.4314/ahs.v17i1.30

Calain, P. (2008). Oil for health in Sub-Saharan Africa: Health system in a 'resource curse' environment. Globalization and Health,4(10). https://oi.org/10.1186/1744-86034-10

Edeme, R. J., Emecheta, C. \& Omeje, M.O. (2017). Public health expenditure and health outcomes in Nigeria. American Journal of Biomedical and Life Sciences, 5(5), 96102. https://doi.org/10.11648/j.ajbls.20170505.13

Fazaeli, A.A., Ghader,i H., Salehi M. \& Fazaeli, A. R. (2016). Health care expenditure and GDP in oil exporting countries: Evidence from OPEC Data, 1995-2012. Global Journal of Health Science, 8(2), 93-98. http://dx.doi.org/10.5539/gjhs.v8n2p93

Farag, M., Nandakumar, A. K., Wallack, S., Hodgkin, D., Gaumer, G., \& Erbil, C. (2013). Health expenditures, health outcomes and the role of good governance. International Journal of Health Care Finance and Economics, 13 (1), 33-52. https://doi.org/10.1007/s10754-012-9120-3

Gani, A. (2009). Health care financing and health outcomes in Pacific Island countries. Health Policy and Planning, 24, 72-81. https://doi.org/10.1093/heapol/czn044

Grossman, M. (1972). On the Concept of Health Capital and the Demand for Health, Journal of Political Economics, 80, 223-255.

Kim, T.K. \& Lane, S. R. (2013). Government health expenditure and public health outcomes: A comparative study among 17 countries and implications for US health care reform. American International Journal of Contemporary Research, $3(9), 8-13$.

Kulkarni, L. (2016). Health inputs, health outcomes and public health expenditure: Evidence from the BRICS countries. International Journal of Applied Economics, 31(1), 72-84.

Martin, S., Rice, N., \& Smith, P. C. (2008). Does health care spending improve health outcomes? Evidence from English programme budgeting data. Journal of Health Economics, 27(4), 826-842. https://doi.org/10.1016/j.jhealeco.2007.12.002

Nikoloski, Z., \& Amendah, D. (2017). Does a country's greater health care spending lead to better health outcomes for its population? -Evidence from African Health Accounts https://afhea.org/docs/analysis-of-health-for-selected-countries.pfd

Nwakanma, P.C., \& Nnamdi. K. C. (2013). HealthCare Financing and Health Profile in West African Countries. http://cega.berkeley.edu/assets/miscellaneous_files/5ABCA-Nnamdi-HealthCare Financing and Health Profile in WAfr.pdf

Rana, R. H., Alam K. \& Gow, J. (2018). Health expenditure, child and maternal mortality 
Opeloyeru, O. S., Lawal, N. A., \& Agbatogun, K. K.

nexus: a comparative global analysis. BMC International Health and Human Rights, 18 (1). https://doi.org/10.1186/s12914-018-0167-1

Riman, H.B., \& Akpan, E. S. (2012). Healthcare financing and health outcomes in Nigeria: A state-level study using multivariate analysis. International Journal of Humanities and Social Science, 2(15), 296-309.

World Health Organization (WHO). (2013). State of Health Financing in the African Region. https://www.afro.who.int/publications/state-health-financing-africanregion

World Health Organization (WHO). (2013). State of Health in the WHO African Region. An analysis of the status of health, health services and health systems in the context of the Sustainable Development Goals.https://www.afro.who.int/publications/state-health-who-african-region 